\title{
Knowledge Management in Global Organisations
}

\author{
Maruf Hasan ${ }^{1} \&$ Songkai Nicholas Zhou ${ }^{1}$ \\ ${ }^{1}$ School of Mechanical and Manufacturing Engineering, University of New South Wales, Sydney, Australia \\ Correspondence: Maruf Hasan, School of Mechanical and Manufacturing Engineering, University of NewSouth \\ Wales, Sydney, Australia. Tel: 61-2-9385-5692. E-mail: m.hasan@unsw.edu.au
}

Received: September 30, 2014

Accepted: May 11, 2015

Online Published: May 25, 2015

doi:10.5539/ibr.v8n6p165

URL: http://dx.doi.org/10.5539/ibr.v8n6p165

\begin{abstract}
Following the information boom that propelled the world into the $21^{\text {st }}$ century, it has become crucial for global organisations to have the ability to convert all precious data to useful knowledge. As a company's tangible assets gradually become far less valuable than its intangible assets, it is essential to learn how to efficiently manage this knowledge. This study analyses how the basic elements of knowledge management are linked to the development of an organisation's competitive edge. It also looks at the level of knowledge management adoption across Asia as compared to the West. Through online research, literature reviews and interviews, this paper presents a series of case studies on knowledge management implementation at various global organisations.
\end{abstract}

Keywords: knowledge, management

\section{Introduction}

Although knowledge has been in existence long before the days of Aristotle and Confucius, it has only come into focus in the past decade. Not surprisingly, the growing importance of knowledge is directly linked to the ever increasing speed at which data can be transferred from one place to another. Due to the technological advancements which gave rise to the Internet Revolution, we now live in a world not only embedded in knowledge, but also more importantly, driven by knowledge.

With the abundance of information in the $21^{\text {st }}$ century, a new challenge of knowing what is useful and what is not has been faced by both individuals and corporations. Possessing the ability to manage and capitalise on new-found knowledge has thus become the difference between success and failure in today's and tomorrow's economies (Tiwana, 2002). Companies must be able to learn, adapt and change quickly according to market forces, and also manage their knowledge resources well. This will enable them to leverage what they know to gain a competitive edge over others.

In order to understand how corporations have changed as knowledge becomes more influential, let us take a look at the global marketplace that we work in today, which is fundamentally different from what it was a hundred years ago. The most prominent difference is the rise in the economic value of intellectual capital over physical capital. In the not too distant past, people were working at individual farms or shops producing goods one at a time. This evolved through the industrial revolution to groups of people working in factories producing hundreds or even thousands of a same product at a time. Up till then, a corporation was valued upon factors such as how much land it owned or how many manufacturing facilities it had. The dawn of the Information Age brought about new companies such as Microsoft, Oracle and Google, which produce virtually no physical assets such as factories or properties and are valued for their intangible assets - knowledge of their employees. Many factors have led to the current rise in importance of knowledge, one of which is realization that emerges after losing it. At the time when many corporations were downsizing to move towards leaner organisations, a great number of experienced engineers and middle-management were retrenched. They took with tem valuable knowledge and experience, which was a great loss to their organization. After realizing the costly errors made in neglecting the importance of knowledge, many companies are now trying to better understand the concept of knowledge and also to explore ways of creating, retaining and using it.

In the knowledge-based economy of today, knowledge has become an essential competitive tool of many businesses. The constantly increasing and changing consumer demands have raised the stakes in global competitiveness. Companies must be able to learn, adapt and change quickly according to market forces, and also manage their knowledge resources well to be able to ensure survival. The joint forces of globalization and 
technology is revolutionising the way companies conduct business and only by leveraging what they know will they gain a competitive edge over others.

In view of the growing importance of managing knowledge, this study will look into one of the most important management tools in use by executives today-Knowledge Management. The success of global organisations is increasingly dependent on their investment in efforts to efficiently acquire and manage knowledge. Henceforth, the problem of how to effectively implement knowledge management to achieve a competitive advantage arises. Knowledge management is a highly complex and wide concept that covers almost every aspect of an organisation. It can be referred to as a tool, a process, or even a discipline. It involves the cultivation of a learning culture within organisations where employees gather knowledge and share it with each other to achieve an improved level of performance in terms of cost savings, efficiency, and competitiveness (Pan \& Scarborough, 1999). Companies will therefore need to first grasp the important concepts before deploying a strategy to transform into a knowledge company.

In the past few years, there has been a growing concern in considering knowledge as a significant organizational resource. With this increasing interest in organizational knowledge and knowledge management, researchers have begun in depth researches on KM. The current literature confirms that KM can be employed in any organization yet not many organizations have thorough and systematic KM programs in use. (Chourides et al., 2003).

Due to the growing attention knowledge management is receiving there are a lot of approaches, perspectives, methods and tools relevant to KM (Hendricks, 2001, (Allameh et al., 2011). In the business world, knowledge appears to be the most significant to sustain business than capital, labour or land (Alavi \& Leidner, 1999; Al-Zegaier, 2012). However, it remained the most neglected asset until recent decades. Acknowledging the importance of knowledge, Peter Drucker (Drucker, 1988) argues that "compared to previous economic development periods, knowledge has become the primary factor in production in the current economy".

\subsection{Objective}

The objective of this paper is to review the various knowledge management initiatives taking place in companies around the world, and study how managing knowledge helps develop an organisation's competitive edge. It also takes a brief look at the development of knowledge management in the most important region of the world today - Asia. Asia is home to the emerging markets and also boasts some of the fastest growing economies in the world. The analysis of awards given to companies based in Asia, as well as reports on Asian companies, will give an indication of the level of knowledge management adoption in this region. The three main objectives are:

1) Identify and understand the key concepts in knowledge management;

2) Review the various knowledge management initiatives in companies;

3) Determine the level of knowledge management adoption in Asia.

\subsection{Methodology}

The paper follows a qualitative research approach. Qualitative research involves a deep understanding of human behavior and the reasons behind it. Leedy and Ormrod (2001) cite that qualitative research usually serves one or more of the following purposes:

- $\quad$ Reveals the nature of certain situations, settings, processes, relationships, systems or people;

- Enables researchers to gain insights into the nature of a particular phenomenon, develop new concepts or theories about the phenomenon, and discover the problems that exist;

- $\quad$ Allows researchers to test the validity of certain assumptions and theories in the context of the real world.

In the study, both empirical and non-empirical methods were employed. Firstly, the non-empirical approach, which was the literature survey, provided a brief outline of the main concepts in the area of knowledge management. Previous studies and literature were reviewed to provide the theoretical groundwork for effective case study. More detailed discussions of the topics in focus for this study were then explored, and that served as the foundation for the empirical research. After which, a series of case studies on knowledge management implementation at various global organisations were presented.

Sources which were used to accumulate theoretical knowledge of the subject include books, and online journals and articles. Keywords used in online search engines include: "knowledge", "knowledge management", "KM" and "successful km organisations". In addition, background information on companies were obtained from the respective company websites. Following that, the empirical research, which consist of a series of case studies, is 
presented. Case studies are generally qualitative and aim to provide a detailed description of a small number of cases (Mouton, 2001). In contrast to surveys, case studies are built upon intensive analysis of individuals or small groups within a specific context, instead of gathering data from a large sample size. For this study, the data collection method of choice was face-to-face and phone interviews. The interviews were conducted, drawing upon the knowledge and experience of representatives from each of the organisatios, whose work was directly or indirectly involved in the field of knowledge management. All companies were selected based on convenience sampling with over forty requests sent out. Out of the forty requests, employees from six companies agreed to be interviewed

\section{Case Studies}

\subsection{Case Study 1}

Company A is a measurement and instrument company that has close to 20,000 employees worldwide located in more than 100 countries. Its main business areas are life sciences and chemical analysis solutions, communications test equipment, as well as test and measurement products. The organisation does not have a company-wide knowledge management initiative in place. Each business unit has their own systems in place to share information but it is not identified under a common knowledge management umbrella.

The knowledge management project in its Singapore contact centre was started when it recognised the need to organise information effectively. Staff at the contact centre understand the importance of managing knowledge through an existing problem and knowledge management was identified as the ideal process to help plug the gap. Inputs from staff were held in high regard as they were involved in all stages in the process of building the system.

The contact centre's knowledge management project involves building a framework to define how information is being displayed. The main idea was to re-design their "web" such that it revolves around the end-user, so as to take away the chore of having to think about where certain information is located. As such, the end-product will be a one-stop webpage which contains everything that the user needs.

The benefits that the organisation hopes to achieve from implementing knowledge management are for agents to find information easily and quickly, resulting in shorter response times to customers-to achieve higher customer satisfaction. In a large organisation where both customers and tools are very complex, there is a tendency for information to be misplaced. To a new employee, it can be a daunting task to figure out where to go for specific information. Being able to get to this information promptly would definitely be in favour of the customer who is ultimately the main beneficiary of this knowledge management project.

This case is an example of a specific department within a large organisation implementing its own knowledge management project. The need to manage knowledge was strongly linked with the need to improve customer satisfaction. Although the department was not given any funding from its headquarters, it still managed to design a system using current resources. A noteworthy aspect is their practice of engaging employees in the design and building phases of the project. By getting employees to contribute, they will have a sense of being part of the whole project. This will lead to a better adoption rate as the system will be built upon the requirements of the users and not just the ideas of the team working on it.

\subsection{Case Study 2}

Company B is a Singapore-based full service bank with more than 12,000 employees and over US\$100 billion in total assets. It has an international presence of branches and representative offices worldwide, in addition to branch networks in key Asian markets.

Company B does not have a formal company-wide knowledge management policy and there appears to be a lack of initiatives with only fragmented attempts to officially manage knowledge. They do however have a knowledge base that includes a resource centre, CRM system, contacts database and an intranet with search portal. This knowledge base was created in 2000 together with its Central Communications department which facilitated its implementation. Product officers submit a write-up of procedures and product information to be included in the knowledge base to the Central Communications Department, which will vet the information before putting it up for other staff to access.

Accuracy of information in the knowledge base is of high importance as it affects the level of service provided to customers, which is one of the main business goals of the company to retain customers. Weekly updates are thus performed by the Central Communications department to keep the information stored current. Access to this knowledge base is limited to an employee's nature of work, with customer information and trends restricted to certain users. There are tools embedded in the system to limit access to restricted data by employees' network 
ID.

A significant barrier to its widespread use is the large number of restricted sites which hinders the transfer of knowledge to employees. Certain individuals who contribute to the knowledge base also make it available only to their own departments and this prevents others from gaining access. Such actions are probably due to the risk of valuable corporate knowledge falling into the wrong hands. There are negative effects though as they become barriers to the free flow of knowledge transfer.

A reason for the lack of knowledge management initiatives at Company B could be due to the history of the company, as the bank was mainly a local business that went global only in the last eight to ten years. Furthermore, banking systems of the past were not very technologically driven and for a long time, the need to manage knowledge was not obvious. As the banking industry gets more competitive and Company B's overseas operations grow bigger, there will be a greater need for knowledge management to transfer best practices from each branch of operation to the other so as to build a competitive advantage. However, due to the confidentiality of the business, there is definitely the need of striking a balance of "who needs what", before knowledge management can be successfully implemented.

\subsection{Case Study 3}

Company $\mathrm{C}$ is the one of the largest IT companies in the world, with US\$100 billion in annual revenue. It is headquartered in the US and employs around 150,000 staff in more than 170 countries around the world.

The company has invested heavily in techniques and tools to promote a culture to share knowledge. Initiatives include basic knowledge-based repositories as well as open cubicles in the office to create a relaxed, open culture for increased human interaction and knowledge sharing. As expected, it has a broad and deep knowledge management program. The fundamentals are based on the fact that success in knowledge management will come from people, processes and technology.

Company $\mathrm{C}$ holds an annual technology conference where commendable articles from their knowledge repository are selected by a panel of judges to be showcased. This encourages employees to submit articles on technology-related stuff as they stand to gain an all-expense-paid trip to the conference as well as recognition for their contribution. During performance appraisal exercises, employees' contribution in terms of the number of quality articles submitted is also analysed as there is a yearly preset quota to reach. This not only shows their willingness to share knowledge but also their level of technical competency.

In 2003, a global knowledge management measurement program was established to evaluate the state of collaboration and status of knowledge management activities. Measuring business processes is essential to ensure that it can be managed effectively. Measurements will show whether the initiatives are accomplishing what they were set out to achieve in the first place. Through measurements and analysis, Company $\mathrm{C}$ hoped to see if knowledge management is making an impact on business growth, cost reduction, and also improving customer relations.

As a global and pioneer IT company with embedded technology that are knowledge management enablers, Company $\mathrm{C}$ saw the need to manage knowledge much earlier that other companies and this also made it easier for them to implement knowledge management at an early stage. The extent of knowledge management adoption at Company $\mathrm{C}$ is very deep as evident from their measurement and rewards programs in place, on top of the usual knowledge management initiatives. This goes to show that they have gone far beyond just implementing knowledge management but have reached the stage where they are interested in the evaluation of its success.

\subsection{Case Study 4}

Company D is a global software giant with over 70,000 employees in more than a hundred countries. It started adopting knowledge management practices when it found that it grew too big to be without it. Now, Company D not only embraces knowledge management by deeply incorporating it into the company's strategy, it also develops and provides knowledge management solutions for other companies.

The company deploys an array of in-house developed knowledge management tools that all employees use to perform their job. This allows them to make their staff believe in their own products before selling it to others. As compared to other companies, Company D has this advantage of already possessing cutting-edge technology and can thus easily push through initiatives. When this advantage is added to their staff's positive sharing culture, the end result is highly effective and successful knowledge management initiatives.

In 1995, Company D set out to map the knowledge of system developers. The aim was to effectively match employees' skills to specific work teams and jobs. This necessity led to the launch of a project to build an online 
knowledge map that can be accessed throughout the company. Its focus was on competencies required to stay on the forefront of the industry.

To begin with, employees were evaluated on their level of competency. With staff competency levels categorised, the next step required managers to rate each job in terms of the number of knowledge competencies required to perform it. In addition, a worker's exhibition of his knowledge level in a current job will also be evaluated. This serves as a conversation opportunity as everyone involved would meet to sort out their different opinions about the employee's competencies. This aims to enable future project managers to be able to search an online system of staff knowledge levels and identify the most suitable candidates to work on an upcoming project.

The program initiative to create a knowledge map is evidence that it strongly values knowledge and supports its exchange. Not only does the initiative succeed in making knowledge easier to locate, the immense benefit that it brings to the company goes far beyond the actual ability of the map itself. The creation of the knowledge map also emphases the ideology that corporate knowledge belongs to the organisation as a whole and not to the individual.

\subsection{Case Study 5}

Company E is a Japanese-based engineering company that manufactures conveyor and robot palletising systems. Since its founding, the company has expanded globally by setting up subsidiaries in Singapore, China, Malaysia, the US, and Europe.

One of Company E's strategic business goals is to further enhance the technical capabilities of their engineers and sales staff through knowledge management so as to raise their overall competency levels. This not only increases the company's competitive advantage but also helps to differentiate themselves from their competitors. The competency level of its engineers is a critical success factor and sharing experiences is one of the most effective ways to enhance the knowledge and skills of employees, and increase awareness amongst the staff. Company E constantly strives to identify and capture knowledge that is essential for the daily work activities of engineers and distributes the knowledge for reuse.

Company $\mathrm{E}$ has a corporate university which is at the core of their knowledge management activities. The university provides professional training programs that are tailored to employees' job scopes and also in line with company objectives. Based on the experiences accumulated by the senior engineers, sales staff and managers of the company, it constantly looks for knowledge and experiences which can be shared and formalised into training programs. As the corporate university is part of the company's organization chart, the knowledge management initiatives are formally sustained and implemented.

Knowledge management at Company $\mathrm{E}$ is still in its infancy stages as it was only implemented in 2006. However, management clearly understands the importance of knowledge management to the long term success of the company. The initiatives that it has implemented or are in the pipeline appear to be quite substantial for an organisation of its size.

\subsection{Case Study 6}

Company F is one of the Big Four accounting firms, employing about 140,000 people in over 100 countries. Its main business areas include audit and assurance, tax, and advisory and consulting.

Its knowledge management system is a company-wide intranet that connects the entire global organisation of partners and employees. It acts as the central communication and knowledge sharing tool for all, which makes it an integral part of the firm's structure. The multi-dimensional design of the system supports communication, continuous learning and virtual office strategies.

It functions as a central source of information to audit professionals and gives the latest audit news updates. It also provides information about company policies, client engagements as well as technological updates. Information captured on the system includes client specific data, past client engagements, standard procedures for each job, methodology, corporate governance, accounting/audit and financial reporting standards, and technological updates. Upon recruitment, audit staff are trained in the use of the system as it will eventually become part of their day-to-day workflow as it is in use all the time.

This is a fine example of a knowledge management system that is fully integrated into the workflow of employees. It is not surprising, that they have an effective knowledge management system in place, as Company F has global operations and their clients operate globally. Hence, they have to build a strong culture of knowledge sharing to "get the job done". It is proven from the fact that an employee is trained in the use of the system right from the beginning of his journey with the firm and is fully engaged with the system throughout the 
course of his work.

During training sessions, staff are briefed about the importance of possessing an insight of client knowledge before performing an audit. Auditors are encouraged to familiarise themselves with client background information and audit procedures from the client database in the knowledge management system. An audit team is briefed before an audit during a "kick-off" meeting by the team manager and senior auditors. Knowledge about the client is then shared with everyone in the team, with the seniors transferring valuable knowledge to junior auditors. Spreading of knowledge helps in the audit engagement process and because of the way the firm is structured, knowledge is never kept from one employee to the other. Through client engagements, knowledge is also captured by employees who upload it into the knowledge management system for verification and storage. This information is then used in future engagements with the client by new teams.

\section{Findings and Conclusion}

The case studies show a varying level of knowledge management adoption amongst the various companies.

Companies like 3, 4, and 6 all well ahead of their peers in the field of knowledge management. On the other hand, Company 1 and 5 are just starting out their first knowledge management projects while Company 2 does not even have a recognized initiative. One reason for the difference might be due to the availability of resources for investment in knowledge management initiatives, while another reason might be because of the varying importance of knowledge to these organisations. Companies like 3, 4 and 6 are knowledge intensive companies where their people are their most important asset and knowledge is the product which they sell. Company 3 and 4 are also technological firms which rose to prominence during the start of the Information Age and they naturally understand the value of knowledge management.

In addition, their in-house expertise in IT technologies also gives them the advantage in implementing knowledge management. After this, the second group of companies are the engineering/manufacturing companies like 1 and 5. Although they are not as knowledge intensive as the previous group, knowledge is still a very important asset of them. These companies hold many other vital physical assets such as manufacturing facilities and equipment. Other financial institutions like banks and brokerages have made little headway in knowledge management of. A possible reason for them not fully embracing knowledge management, is the fact that they hold a lot of proprietary knowledge which cannot be shared and so, initiatives that promote the transfer of knowledge are not suitable.

From the case studies, it can also be gathered that most companies implement knowledge management as a way to improve customer service. Amongst the entire list of benefits that firms hope to achieve from managing knowledge, the most prominent one is the focus on customer satisfaction. As evident in almost all the case studies, knowledge management tools in many companies allow employees quicker access to information. More importantly, most knowledge transfer tools used by companies aim to deliver the right information at the right time and this is geared towards faster customer responses.

In both financial and human aspects, resource is the key factor that drives knowledge management initiatives. As a known fact, a significant amount of investment is required for any management initiative. From the hardware systems used to support knowledge repositories to the knowledge tools used for the transfer of knowledge, all these represent added costs to an organisation's bottom line. Large organisations such as MNCs and government agencies have an edge over SMEs in the sense that they have enviable resources to invest in their knowledge management efforts. Companies that have made significant strides in knowledge management such as Company 4 and 6 have enviable financial resources to invest in their knowledge management efforts. Even in the event of a business downturn, they are still able to pump in considerable investments into knowledge management initiatives and emerge even more competitive when business picks up. Compare this to smaller companies like Company 5 that will probably have to shelve their knowledge management plans during a recession in order to cut costs, and it is obvious why the annual Global MAKE awards are mostly (if not totally) bestowed upon large corporations.

However, SMEs can still implement knowledge management with almost no resources. They can make significant progress by having a clear strategy and detailed plan on how they intend to go about managing their own knowledge. Even without much allocated resources, SMEs can engage the participation of all staff, who will be eventual users of the system, to contribute in the development of the project. These user inputs are crucial in amplify the needs that require the knowledge management system to adhere to. This ensures a high adoption and also success rate as the knowledge system built would have developed from the needs of the users instead of being solely based on the objectives set by management. 
As such, there is also no general knowledge management solution that can be applied across the board for all companies. Based on their individual needs and means, each company or even each business unit has to adopt their own knowledge management initiatives that best suits their organisation.

Another challenge facing successful knowledge management implementation is motivating people to share knowledge. This might be a cultural or personal barrier that has to be overcome through the cultivation of an organizational knowledge sharing culture. It is observed in almost all the case studies, that most employees at successful knowledge sharing companies are motivated to share because they want to benefit from others' sharing too. In Company 1 and 5 sharing is part and parcel of every client management. Employees at Company 3 create and share knowledge to gain recognition and also to hope to win a free trip to attend an annual conference.

User inputs during the development phase of any knowledge management initiative is crucial in ensuring its success. User inputs were essential in Company 6's knowledge audit process. It enabled them to assess their knowledge management initiatives and further develop them through identifying and fixing existing problems. Company 3's management gathers input from staff through its worldwide employee survey to implement changes to their knowledge management systems. Similarly at Company 4, staff feedback on the knowledge tools that they use every day and this enables management to ensure that the tools are effective. Company 3's customers also use their knowledge management system, and are encourages to provide feedback through customer satisfaction surveys.

A trend that is observed from the case studies is the approach that companies take towards knowledge management implementation. Most of the larger corporations with diversified businesses like Company 1, 3 and 4 tend to have knowledge management initiative at a division or even department level. Each division has its own needs. A central knowledge management department at corporate level will look into the various projects going on around the company and provide assistance or promote the successful projects for adoption at other divisions. In fact in Company 1, knowledge management actually began as projects from the individual business units as a bottom-up approach. For smaller companies like 5, knowledge management is adopted with a top-down approach. This is because individual departments are too small and do not have the resources to implement their own knowledge management initiatives. Due to the smaller revenue generated, even country-level subsidiaries do not have the funding to implement their own projects. As such, headquarters has to pull resources together to develop a common knowledge management initiative for the various subsidiaries to adopt for their own use. On the other hand a company like 6 is a large organization whose few consolidated business units have very similar needs with respect to managing knowledge. Their approach to knowledge management would be similar to the small organisations' top-down approach, whereby the central knowledge management department develops and pushes through initiatives company-wide. Therefore, there is no general knowledge management solution that can be applied across the board for all companies. Based on their individual needs, each company or even each business unit has to adopt their own knowledge management initiatives that best suits their organization.

Knowledge management has been a well-established management concept in the West for quite a while but it has only emerged in Asia not too long ago. However, due to the cultural differences, the context in Western and Asian organisations is different. Culture defines what knowledge is and also characterises the relationship between individual and corporate knowledge. It designates the social settings where knowledge is shared and outlines the processes for creating, organising and disseminating knowledge.

In Asian subsidiaries of Western companies that were interviewed, local employees have adapted to the culture and practices of their parent companies. As such, they are more open to sharing what they know with others and participate in knowledge-sharing activities. The adoption level of knowledge management in these local subsidiaries would thus be similar to their parent companies. In contrast, Asian-bred companies have a reluctance to share, as sharing of knowledge might reduce the competitive edge of an individual. This might be a barrier to knowledge management efforts that promote sharing and would result in a low adoption rate in these companies.

The turning point for Asia could be the 1997 Asian economic crisis, which forced companies in the region to take a step back to review their business and organisational strategies. After that fateful year, Asian companies began to realise that they have to change their practices to better position themselves for competition in the new knowledge economy. As such, the idea of knowledge management and the benefits that it could bring was suddenly looked upon with renewed interest. The annual Global MAKE study shows that knowledge management is gaining momentum in countries across this region, with a $20 \%$ increase in the number of Asian finalists and a 30\% increase in the number of winners of the annual Global MAKE award from 1998 to 2006. 
The greater representation by Asian firms in this award can definitely be attributed to the increased adoption level in the region.

Nevertheless, Western (North America, EU and Global) companies still hold a majority based on the percentage $(70 \%)$ of their winners of the Global MAKE award 2006. From this, Asia still lags behind Western countries in terms of the general adoption level of knowledge management. Despite this, there are a few notable firms leading the way in Asia such as Toyota, Honda Motor, Sony, Samsung Group and Tata Group. Hopefully, they will lead the drive to promote knowledge management in Asia.

Judging from the number of articles posted as well as books written on the subject, interest in knowledge management peaked just around the turn of the century. After which, there seemed to be a decline in the level of knowledge management activity. One reason might be the shift of focus to other management tools due to the length of time it takes to realize the gains of knowledge management. Many short-sighted management executives would rather turn to cost cutting measures to improve their bottom line rather than continue their investment in knowledge management efforts that will ensure the future sustainability of their companies.

Nonetheless, the 2007 report by Bain \& Co. on Management Tools and Trends shows that knowledge management had moved into the top ten most used tools in 2006. It is thus evident that knowledge management is making a recent comeback as the global economy evolves into a knowledge-based one. The future looks bright for knowledge management as it would definitely be the way to go for years to come. As companies start to realise that the ability to successfully manage knowledge is fast becoming a crucial way to compete, they will look to knowledge management to boost their competitive advantage. Indeed, it will exist at the core of most organisations in the knowledge-based economy of the future.

\section{Acknowledgement}

This is an extended version of a paper presented at the ICIT (International Conference on ISO and TQM) in Kuala Lumpur, Malaysia.

\section{References}

Ai-Zegaier, H. B. (2012). Mobile knowledge portals: A new way of accessing corporate knowledge. American Academic \& Scholarly Research Journal, 4, 1-7.

Alavi, M., \& Leidner, D. E. (1999). Knowledge management systems: Issues, challenges, and benefits.

Allameh, S. M., Zare, S. M., \& Davoodi, S. M. R. (2011). Examining the impact of KM enablers on knowledge

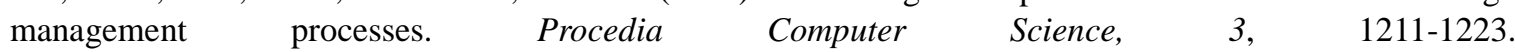
http://dx.doi.org/10.1016/j.procs.2010.12.196

Bellinger, G. (2004). Knowledge management-Emerging perspectives. Retrieved 27 October, 2007 from http://www.systems-thinking.org/kmgmt/kmgmt.htm

Chourides, P., Longbottom, D., \& Murphy, W. (2003). Excellence in knowledge management: An empirical study to identify critical factors and performance measures. Measuring Business Excellence, 7, 29-45.

Davenport, T. H., \& Prusak, L. (2000). Working knowledge. Boston: Harvard Business School Press. http://dx.doi.org/10.1108/13683040310477977

Davenport, T. H., \& Volpel, S. C. (2001). The rise of knowledge towards attention management. Journal of Knowledge Management, 5(3). http://dx.doi.org/10.1108/13673270110400816

Drucker, P. F. (1998). The coming of the new organisation. Harvard Business Review on Knowledge Management. NY: Harvard Business School Press.

Haghi, G. (2004). Measuring knowledge management at HP services consulting \& integration. Proceedings of I-KNOW'04.

Harvard Business Review. (1998). Harvard Business Review on Knowledge Management. Harvard Business School Press.

Hay, D. C. (1999). About knowledge management. Retrieved 27 October, 2007 from http://www.essentialstrategies.com/publications/knowledge/introknowledge.htm

Hendriks, P. H. J. (2001). Many rivers to cross: from ICT to knowledge management systems. Journal of Information Technology, 16, 57-72. http://dx.doi.org/10.1080/02683960110054799

Leedy, P. D., \& Ormrod, J. E. (2001). Practical research: Planning and design (7th ed.). Upper Saddle River, NJ: Merrill Prentice Hall. 
Mouton, J. (2001). How to succeed in your masters and doctoral studies: A South African guide and resource book. Pretoria: Van Schaiks.

Munro, M. (2004). Driving organisational performance through KM. Retrieved 27 October, 2007 from http://www.ikmagazine.com/xq/asp/sid.0/articleid.51AEF1DF-3C72-486F-92DC-28E62A04C0B1/qx/displ ay.htm

Nonaka, I., \& Takeuchi, H. (1995). The knowledge-creating company. New York: Oxford University Press.

Pan, S. L., \& Scarbrough, H. (1999). Knowledge management in practice: An exploratory case study. Technology Analysis and Strategic Management, 11(3). http://dx.doi.org/10.1080/095373299107401

Roberts, J. (2000). From know-how to show-how? Questioning the role of information and communication technologies in knowledge transfer. Technology Analysis and Strategic Management, 12(4). http://dx.doi.org/10.1080/713698499

Rowley, J. (2000). From learning organisation to knowledge entrepreneur. Journal of Knowledge Management, 4(1). http://dx.doi.org/10.1108/13673270010315362

Sieloff, C. G. (1999). If only HP knew what HP knows: The roots of knowledge management at Hewlett-Packard. Journal of Knowledge Management, 3(1). http://dx.doi.org/10.1108/13673279910259385

Tiwana, A. (2002). The knowledge management toolkit: Orchestrating IT, strategy, and knowledge platforms (2nd ed.). NJ: Prentice Hall.

\section{Copyrights}

Copyright for this article is retained by the author(s), with first publication rights granted to the journal.

This is an open-access article distributed under the terms and conditions of the Creative Commons Attribution license (http://creativecommons.org/licenses/by/3.0/). 